University of Nebraska - Lincoln

DigitalCommons@University of Nebraska - Lincoln

7-2009

\title{
Deshaciendo los nudos: Fetichismo y feminidad en la obra de Jasone Osoro
}

Iker González-Allende

University of Nebraska-Lincoln, igonzalezallende2@unl.edu

L. Elena Delgado

University of Illinois, Urbana-Champaign

Follow this and additional works at: https://digitalcommons.unl.edu/modlangspanish

Part of the Modern Languages Commons

González-Allende, Iker and Delgado, L. Elena, "Deshaciendo los nudos: Fetichismo y feminidad en la obra de Jasone Osoro" (2009). Spanish Language and Literature. 30.

https://digitalcommons.unl.edu/modlangspanish/30

This Article is brought to you for free and open access by the Modern Languages and Literatures, Department of at DigitalCommons@University of Nebraska - Lincoln. It has been accepted for inclusion in Spanish Language and Literature by an authorized administrator of DigitalCommons@University of Nebraska - Lincoln. 


\title{
Deshaciendo los nudos: Fetichismo y feminidad en la obra de Jasone Osoro
}

\author{
Iker González-Allende, University of Nebraska-Lincoln \\ L. Elena Delgado, University of Illinois, Urbana-Champaign
}

Yet each man kills the thing he loves.

(Oscar Wilde)

No siempre hay que creer lo que el espejo dice.

Tu rostro verdadero puede ser cualquier máscara.

(Ana Rossetti)

Ella encima de él, los dos desnudos. Los brazos de él, alargados, sujetando la cabeza de ella. Ella, con los brazos cruzados y las manos a los lados de la cabeza de él. Esta descripción corresponde a la portada del libro de relatos y poemas titulado Korapiloak ('Nudos') (2001), de la escritora vasca Jasone Osoro, y de su traducción Desnudos (2002), realizada por la misma autora (Figure 1). La imagen de la portada anticipa la temática principal que la obra desarrolla: la sexualidad y el erotismo en el contexto de las relaciones heterosexuales, relaciones marcadas por las dificultades de comunicación y la dominación del hombre sobre la mujer. Asimismo, la original postura que forman el hombre y la mujer con sus cuerpos anuncia las múltiples modalidades de sexualidad que se reflejan en el libro, entre las que se incluyen la masturbación, la prostitución, el incesto, el voyeurismo y el fetichismo. En cierto modo, como ocurre siempre con el arte erótico, la portada convierte al lector en un espectador de la escena íntima captada en la fotografía: ya de entrada, esta representación visual nos introduce al mismo mundo que viven los protagonistas de los cuentos. El voyeurismo, tema que centra varios de los relatos, sirve así también como reclamo publicitario para la obra, que en efecto ha disfrutado de un gran éxito de ventas. En este trabajo nos proponemos analizar la representación y funcionalidad de la sexualidad en este libro de Osoro, prestando particular atención a la presencia del fetichismo, el cual nos parece un punto de anclaje importante para la reflexión sobre la feminidad que plantea la escritora vasca. Deseamos proponer que, más allá de la reclamación de la liber- 


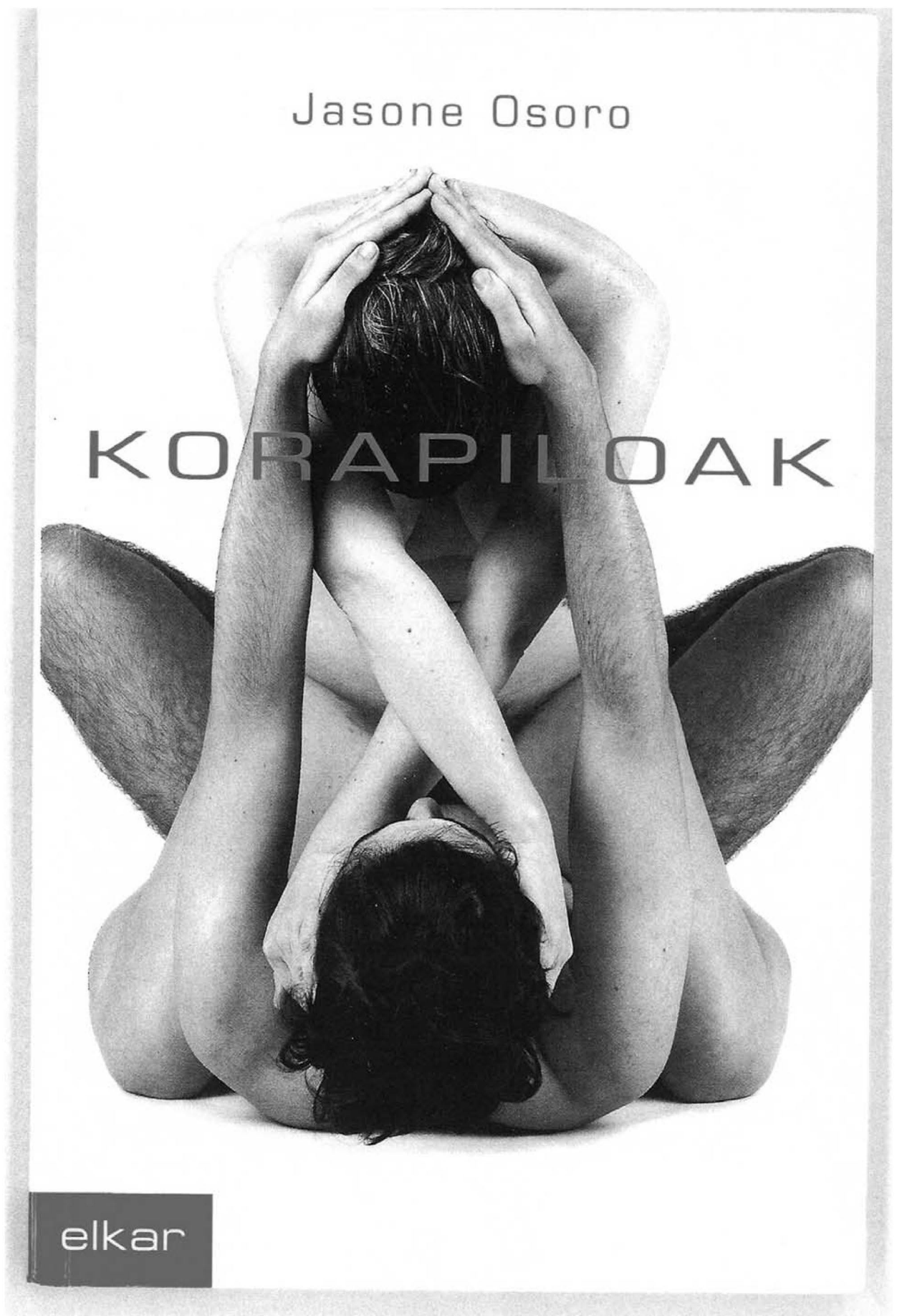

Figura 1. Portada de Korapiloak (2001) de Jasone Osoro (Fotografía de Juantxo Egaña y Eli Gorostegi) Reproducción autorizada por la casa editorial Elkar (Donostia) 
tad sexual y vital de la mujer - postura que se encuentra en otras narradoras contemporáneas del panorama literario del estado español-, el libro de Osoro demuestra que dicha liberación depende en gran medida de los condicionantes sociales que rodean a la mujer. Por otro lado, tampoco se debe olvidar que en el contexto euskérico en que la obra original fue escrita, donde es notoria la ausencia de textos que versen sobre cuestiones sexuales, el mensaje de la autora resulta más innovador y rupturista.

Jasone Osoro nació en Elgoibar (Gipuzkoa) en 1971. Pertenece al grupo de los nuevos narradores vascos en euskera, en el que encontramos nombres como Unai Elorriaga (Premio Nacional de Narrativa 2002 con SPrako tranbia), Harkaitz Cano, Kirmen Uribe o Ixiar Rozas. ${ }^{1}$ Osoro estudió Periodismo y ha trabajado como columnista en varios diarios y como guionista y presentadora en la televisión vasca. ${ }^{2}$ En 1998 comenzó su carrera literaria con una biografía de la bailarina Isadora Duncan. Ese mismo año publicó el libro de relatos Tentazioak ('Tentaciones', no traducido todavía al castellano), en el que ya indagaba en las relaciones entre el hombre y la mujer y utilizaba el sexo como uno de los temas recurrentes. Con ese texto ganó el Premio Zazpi Kale a la obra más vendida en euskera en el Día del Libro de Bilbao. En 2001 publicó Jara, que se enmarca dentro de la literatura juvenil, y finalmente en 2003 salió a la luz Greta (traducida al castellano en 2007), novela en la que, a través de la historia de un joven que vive con un maniquí, se percibe su interés continuado por el fetichismo.

Desnudos se divide en diecisiete relatos, a los que acompaña el mismo número de poemas. ${ }^{3}$ Esta combinación de distintos géneros literarios es una de las características que María José Olaziregi señala como propias de la narrativa vasca actual, ${ }^{4} \mathrm{y}$ que, en general, podemos encontrar en casi todos los

1 En el panorama de la narrativa euskérica contemporánea destacan otros nombres de escritoras como Yolanda Arrieta, Itxaro Borda, Arantxa Iturbe, Mailuix Legorburu, Miren Agur Meabe y Ana Urkiza (María José Olaziregi Alustiza, 'Bibliografía de jóvenes narradoras en vasco', en Mujeres novelistas: jóvenes narradoras de los noventa, ed. Alicia Redondo Goicoechea [Madrid: Narcea, 2003], 221).

2 En concreto, Jasone Osoro ha sido columnista para los periódicos El Diario Vasco y Gara, y ha trabajado para programas de la televisión vasca como Bai zera, Sorginen laratza, Hasiberriak y Goenkale. También ha ejercido como directora de la revista Asteon, la primera publicación periódica sobre televisión escrita en euskera. La compaginación de estas actividades con su carrera literaria muestra lo difícil que les resulta a los jóvenes autores en euskera vivir sólo de su escritura. Al tratarse de una literatura minoritaria, los escritores euskaldunes logran reconocimiento en España y en el extranjero sobre todo cuando sus obras son traducidas, como les ha sucedido a Bernardo Atxaga y Ramón Saizarbitoria.

3 El cuento en euskera adquiere gran desarrollo a partir de la década de los ochenta, sobre todo porque es la modalidad escogida preferentemente por los escritores jóvenes antes de dar el salto a la novela (Xabier Mendiguren Elizegi, 'El cuento en Euskadi: balance de dos décadas', Ínsula. Revista de Letras y Ciencias Humanas, 623 [1998], 27-29 [p. 28]). Actualmente se puede decir que el cuento en euskera presenta un futuro esperanzador gracias a nuevos autores como Harkaitz Cano, Jokin Muñoz, Patxi Iturregi y la propia Jasone Osoro.

4 María José Olaziregi, 'La novela vasca: márgenes, centros y demás limitaciones topológicas', Ínsula. Revista de Letras y Ciencias Humanas, 654 (2001), 17-20 (p. 20). 
textos postmodernos. A pesar de la fragmentación del material, enfatizada por las diferencias formales entre los dos tipos de discursos, Osoro consigue dotar a su libro de unidad a través de la ligazón temática entre ambos géneros literarios, ya que precediendo a cada cuento incluye un poema que adelanta la trama de la narración. Esta táctica de la anticipación enfatiza de nuevo el papel del lector: dado el contenido erótico, es inevitable pensar en los poemas como una especie de cebos literarios que nos invitan a intentar adivinar el argumento del relato que sigue y el tipo de tratamiento que se le va a dar.

El otro recurso que utiliza Osoro para conferir sensación de unidad a su obra es la aparición de algunos protagonistas como personajes secundarios en otros cuentos. Generalmente las referencias a estos personajes no se hacen de manera directa - por ejemplo llamándoles por su nombre-, sino de forma velada, ofreciendo algún dato físico o información que sirva para identificarlos. Esto es, para poder desatar los nudos narrativos que presenta la autora, el lector debe mirar a los protagonistas con sus mismos ojos o desde su misma perspectiva, prestando atención al aspecto externo de determinados personajes que llama la atención de los narradores: un lunar en la mejilla, unas pestañas plateadas o unos zapatos de tacón.

En Desnudos se desarrolla toda una gama de experiencias sexuales que pueden considerarse no normativas o no tradicionales. Las historias incluyen a un hombre que compra una muñeca hinchable para satisfacer sus fantasías eróticas, que consisten también en espiar voyeurísticamente a su vecina; una mujer que se besa con un desconocido de raza gitana en el metro; un joven con atracción edípica hacia su madre; una anciana telefonista de una línea erótica; un hombre que paga a una prostituta sólo para verla masturbarse; una mujer que se casa con un motero de la edad de su hijo; o una prostituta que, tras limpiar casas, resuelve volver a 'hacer la calle' porque considera que limpiar lo que otros ensucian es también una forma de prostitución. Todas estas historias están enmarcadas en un episodio de violencia desarrollado en el primer y el último cuento, en los que Fermín mantiene secuestrada a Rebeca durante quince días, tras los cuales la viola y la mata porque ella no quiso casarse con él. Durante su encierro, Rebeca escribe sobre sus vecinos el resto de los cuentos y poemas del libro, lo que se sabe porque Fermín descubre un cuaderno suyo titulado precisamente Desnudos. Así, en uno de esos giros metaliterarios tan frecuentes en la literatura actual, el lector lee al mismo tiempo que Fermín las historias y los versos escritos por Rebeca.

La presencia de este marco de violencia y muerte en torno al sexo, junto con una visión pesimista sobre las relaciones entre los hombres y las mujeres, podría incluir a Desnudos dentro de lo que Eva Legido-Quigley considera narrativa erótica femenina de carácter tanático, que ella sitúa en España a partir de mediados de los ochenta, y entre cuyas cultivadoras destaca a autoras como Mercedes Abad, Almudena Grandes y Ana Rossetti. Según LegidoQuigley, este tipo de narración presenta una postura antivitalista y una 
visión nihilista de la realidad. ${ }^{5}$ Ahora bien, si la aparición de la violencia y la muerte son factores indudables en cierto tipo de narrativa erótica femenina, su funcionalidad difiere dependiendo del contexto que desarrolle cada obra. En el caso de Osoro, las manifestaciones del masoquismo o del sadismo no se muestran como fuente de placer para la mujer, sino para el hombre. Asimismo, ese placer violento se representa como inseparablemente ligado al poder del hombre en una sociedad patriarcal.

En cualquier caso, es indudable que el énfasis en las vivencias sexuales transgresoras ha funcionado a favor del éxito comercial de la obra. De hecho, la versión en euskera ganó el Premio Euskadi de Plata por sus buenas ventas. Externamente, no sólo la portada, sino también la elección del título del libro en castellano-'desnudos', en vez de la traducción literal del título en euskera, 'nudos' - se podrían interpretar como una estrategia de marketing, ya que no cabe duda de que el sexo vende. Por otro lado, como indica Laura Freixas, la industria editorial utiliza el sexo y la edad como categorías para clasificar a los autores, destacando sobre todo a las mujeres y a los jóvenes porque todavía resultan una novedad en el ámbito literario. ${ }^{6}$ En este sentido, Osoro ha sabido utilizar los medios de comunicación para promocionar sus obras, subrayando su condición femenina y actuando de forma relativamente polémica. Por ejemplo, Osoro se declara abiertamente feminista y señala que toda mujer debería serlo por la desigualdad social entre ambos sexos. ${ }^{7}$ Esta postura de transgresión y reivindicación de los derechos de la mujer ha cooperado, sin lugar a dudas, a las buenas ventas de sus obras, ya que según datos recientes, en el estado español las mujeres leen más que los hombres, y por lo tanto, compran también más libros. ${ }^{8}$

El éxito de Desnudos debe ser enmarcado también en el contexto original euskérico en que surge la obra, lo cual quiere decir que sus puntos de referencia no pueden limitarse al de otras escritoras del estado español como Lucía Etxebarria, Almudena Grandes, Rosa Montero y Ana Rossetti. En este sentido, creemos fundamental no minimizar la originalidad de un texto que rompe con la tradición masculinista predominante en la literatura vasca, excepcionalmente reticente a explorar la intimidad emocional, y aún más la sexualidad. De hecho, hasta la fecha de hoy, el número de escritoras jóvenes reconocidas

5 Eva Legido-Quigley, ¿Que viva Eros? De la subversión postfranquista al thanatismo postmoderno en la narrativa erótica de escritoras españolas contemporáneas (Madrid: Talasa, 1999), 1617. Frente a las novelas de carácter tanático, Legido-Quigley ensalza la literatura erótica femenina que se aproxima a Eros - en la que sitúa a autoras como Consuelo García, María Jaén, Esther Tusquets y Ana María Moix -, porque, en su opinión, manifiesta una actitud vitalista y celebra los deleites del placer sexual (16).

6 Laura Freixas, Literatura y mujeres: escritoras, público y crítica en la España actual (Barcelona: Destino, 2000), 37.

7 Jasone Osoro, 'Feminista naiz', Deia, 8 de marzo de 2007; http://www.deia.com/es/impresa/2007/03/08/bizkaia/iritzia/344686.php, pár. 1.

8 Véase Christine Henseler, Contemporary Spanish Women's Narrative and the Publishing Industry (Urbana: Univ. of Illinois Press, 2003), 10. 
en la literatura en euskera es relativamente reducido, lo que ha provocado que Osoro haya sobresalido en un mercado dominado por los hombres.

Si por un lado es crucial no olvidarse del marco concreto (social, literario, lingúístico) en que se origina esta obra, por otro la propia temática de ésta, junto a la ausencia de referencias espaciales o políticas concretas, posibilita que Desnudos pueda llegar a un público muy amplio. Se podría decir, en cierto modo, que es un libro de fácil 'traducción', lo cual puede entenderse desde dos posiciones diferentes: una, que reclama para las literaturas en lenguas minoritarias su capacidad para ocuparse de cualquier tema, evadiendo la restricción a 'lo local'; y una segunda posición que subrayaría que en estas historias sin localización específica, sin alusiones históricas ni contextuales, la especificidad cultural queda diluida. No hay que olvidar, sin embargo, que la autora escribe en euskera originalmente y la elección de escribir en una lengua minoritaria supone ya en sí misma una reivindicación de esa cultura. Más aún, como indica Joseba Gabilondo en referencia al primer libro de cuentos de Osoro, los textos de esta joven escritora presentan un nuevo sujeto nacional vasco que ya no es masculinista y político, sino femenino, individual, apolítico y sexualmente activo. ${ }^{9}$ Aunque no todo el mundo pueda estar de acuerdo con la posicionalidad adoptada por Osoro, no cabe duda de que su utilización del euskera para crear una narrativa feminista, intimista y erótica marca un antes y un después en la narrativa escrita en este idioma.

El éxito de ventas y la atención pública que ha recibido Desnudos ha provocado que algunos críticos hayan reaccionado negativamente contra lo que identifican como el componente sórdido de la obra y la utilización 'superficial' de la sexualidad. ${ }^{10}$ Esto no es exclusivo de Osoro, ni siquiera de la narrativa contemporánea; como bien ha estudiado Wadda Ríos-Font, es una reacción frecuente a la literatura con fuerte componente sentimental o erótico, particularmente si está escrita por mujeres, a la que se suele clasificar como infraliteratura y/o mero producto de consumo de masas. ${ }^{11}$ En respuesta a este tipo de comentarios negativos contra su escritura, en una entrevista del 2004 con Ana Unanue en la revista Aizu, Osoro se lamenta de que cuando una mu-

9 Joseba Gabilondo, 'Before Babel: Global Media, Ethnic Hybridity, and Enjoyment in Basque Culture', Revista Internacional de Estudios Vascos, 44:1 (1999), 7-49 (p. 31).

10 Un ejemplo de este tipo de crítica se encuentra en la reseña que del libro de Osoro realiza Antonio Ruiz Vega, quien subraya su carácter popular al escribir que 'cualquier mindundi se lo lee en una tarde' y que 'estos éxitos fulgurantes, de la noche a la mañana, cuando no hay detrás una trayectoria muy consistente, atraen siempre la sospecha de que estemos ante un montaje mediático' ('Desnudos'; http://www.comentariosdelibros.com/come-lqhl/book0044-lqhl.htm, pár. 2). Ruiz Vega también parece esconder una especial animadversión contra la identidad vasca de Osoro. Así, se deleita en señalar todos los errores ortográficos de la edición en castellano, de los que culpa a la autora por haber sido ella la traductora.

11 Wadda C. Ríos-Font, 'Eroticism and Canonicity at the Spanish Fines de Siglo', en The Canon and the Archive: Configuring Literature in Modern Spain (Lewisburg: Bucknell U. P., 2004), 164-86 (pp. 183-85). 
jer publica una obra se hable de 'boom' o de estrategia publicitaria, mientras que no ocurre lo mismo cuando el autor es un hombre: 'Kontua da emakume batek liburua ateratzea booma dela, edo moda, edo estrategia komertziala da. Zergatik sufritu behar dugu guk hori guztia? Gizonezko batek ateratzen duenean, berriz, ez da notizia' ('Lo que ocurre es que el hecho de que una mujer publique un libro es un 'boom', o una moda o una estrategia comercial. ¿Por qué hemos de sufrir nosotras todo esto? Cuando un hombre publica un libro, en cambio, no es noticia'). ${ }^{12}$ En referencia al aspecto comercial de sus obras, Osoro se muestra relativamente ambigua. Por un lado, reconoce que el ser mujer, joven y escribir sobre erotismo ha servido para promocionar sus libros, pero que ha demostrado que su labor literaria no es efímera, pues ha seguido publicando. También señala que no escribe para vender más o menos, sino que escribe lo que siente. Sin embargo, seguidamente indica que la literatura se hace para ser consumida y para transmitir: 'Literatura beste gauza askoren artean komunikazioa da, eta idazle guztiok iritsi nahi dugu jendearengana' ('La literatura, entre otras muchas cosas, es comunicación, y todos los escritores queremos llegar a la gente'). Es interesante notar su postura defensiva al anticipar una reacción negativa a su obra en el contexto de la literatura euskérica, en cuyo canon no espera ser incluida: 'Ez da nire asmoa euskal literaturaren entziklopedian urrezko letrekin agertzea' ('No es mi objetivo entrar con letras de oro en la enciclopedia de la literatura vasca') ${ }^{13}$ De esta manera, Osoro presenta una relación contradictoria con los medios de comunicación, ya que por un lado, no le agrada que, por servirse de ellos, la etiqueten como una escritora poco seria, pero por otro lado, sabe que su éxito depende en gran medida de su presencia en los periódicos y la televisión.

12 Ana Unanue, 'Jasone Osoro: Ez dakit ezetz esaten', Aizu, enero de 2004; http://www. elkarlaneanfundazioa.org/hemeroteka/aizu_greta_2004-01.htm, pár. 12. Las traducciones del euskera al castellano a lo largo del artículo han sido realizadas por Iker González-Allende.

13 Unanue, 'Jasone Osoro', pár. 9. De hecho, no existen mujeres en el canon de la literatura en euskera. Por ejemplo, en la lista de escritores vascos canonizados en las últimas décadas, Jon Kortazar sólo incluye a hombres: Txillardegi, Ramón Saizarbitoria, Bernardo Atxaga y Anjel Lertxundi ('El canon de la literatura vasca', Ínsula. Revista de Letras y Ciencias Humanas, 600 [1996], 22-24 [p. 24]). Linda White se lamenta de esta situación y opina que los críticos vascos han juzgado las obras de las escritoras más severamente que las producidas por hombres ('Emakumeen hitzak euskaraz: Basque Women Writers of the Twentieth Century' [Diss. Univ. of Nevada, Reno, 1996], 313). Además, White considera que no se han valorado lo suficientemente las obras pedagógicas o de literatura infantil escritas por mujeres ('Mission for the Millennium: Gendering and Engendering Basque Literature for th e Next Thousand Years', en Basque Cultural Studies, ed. William A. Douglass, Carmelo Urza, Linda White y Joseba Zulaika [Reno: Univ. of Nevada Press, 2000], 134-48 [p. 139]). La misma opinión presenta Joseba Gabilondo, pero explica la ausencia de nombres de mujer en el canon como resultado de que autoras como Arantxa Urretabizkaia, Mariasun Landa, Laura Mintegi y Arantxa Iturbe se alejen del imaginario nacionalista vasco, donde la única mujer existente es la madre ('Del exilio materno a la utopía personal: Política cultural en la narrativa vasca de mujeres', Ínsula. Revista de Letras y Ciencias Humanas, 623 [1998], 32-36 [p. 35]). 
La situación de Osoro es similar a la de Lucía Etxebarria en el mercado literario español en castellano: a ambas se les acusa de ser productos comerciales, de generar polémicas y de tratar temas sexuales en sus obras para vender más ejemplares. Dejando al margen la particular evaluación de su producción, lo que es indudable es que, como apunta Silvia Bermúdez, Etxebarria ha sabido utilizar los medios de comunicación para promocionarse a sí misma y publicitar sus escritos. ${ }^{14}$ Ahora bien, tanto en el caso de Etxebarria como en el de Osoro, existe un proyecto muy específico de indagar en lo que a menudo se considera 'superficial', y a través de ese análisis llegar a una crítica de una sociedad patriarcal donde la sexualidad femenina aparece todavía subsumida en unos marcos que la niegan o desvirtúan. Asimismo, ambas autoras cuestionan de forma explícita la ilusión de que el éxito literario es independiente de las cuestiones de mercado y de las estrategias de publicidad, revelando de esta forma que la industria del libro es un negocio, algo que las instituciones literarias españolas desean esconder. Por lo tanto, tanto Osoro como Etxebarria no sólo aceptan, sino que juegan con la dimensión de mercancía de sus libros: es como si quisieran subrayar que la relación entre el público y el libro no es tan diferente de la que se establece con otro tipo de productos en una sociedad controlada por el fetichismo de la mercancía. Por este motivo, no parece casual que varios de los cuentos de Desnudos enfaticen la comercialización y el consumismo de la vida cotidiana, que afecta a todas las facetas de la vida, incluyendo la sexualidad. Esto explica que en la obra el fetichismo sea precisamente uno de los aspectos más destacables en la exploración del erotismo y la sexualidad de los personajes.

Entre los diversos fetiches que aparecen en Desnudos se encuentran la muñeca hinchable, la mujer muerta, la niña, los labios pintados de carmín rojo, la lencería o los zapatos de tacón. El tratamiento que se da a esta variedad de objetos de deseo parece en cierto modo querer 'normalizarlos', subvirtiendo así los modelos tradicionales de sexualidad. Por otro lado, también es cierto que los relatos suelen narrarse desde la perspectiva de los protagonistas, por lo que resulta lógico que sus fetichismos se presenten como experiencias sexuales 'normales'. Como es sabido, se entiende por fetichismo sexual el hecho de que un objeto inanimado o una parte del cuerpo humano se conviertan en el centro de la preferencia sexual de una persona. ${ }^{15}$ En el ensayo Fetishism (1927), Freud explicaba este fenómeno como consecuencia de la ansiedad de la castración y señalaba que el fetiche es un sustituto del pene que

14 Silvia Bermúdez, 'Let's Talk about Sex?: From Almudena Grandes to Lucía Etxebarria, the Volatile Values of the Spanish Literary Market', en Women's Narrative and Film in Twentieth-century Spain: A World of Difference(s), ed. Ofelia Ferrán y Kathleen M. Glenn (New York: Routledge, 2002), 223-37 (p. 225).

15 Lorraine Gamman y Merja Makinen, Female Fetishism (New York: New York U. P., 1994), 37. 
el niño pensaba que su madre poseía. ${ }^{16}$ Numerosas investigadoras feministas han rechazado esta teoría basada en una visión falocéntrica de la sexualidad que encierra un claro componente misógino. ${ }^{17}$ Así, autoras como Hélène Cixous, Luce Irigaray y Julia Kristeva, entre otras, han analizado el fetichismo centrándose en la etapa pre-edípica u oral en vez de la etapa genital. De esta manera, el fetichismo surgiría como consecuencia de la ansiedad de la separación y no sería, por tanto, un fenómeno exclusivamente masculino. ${ }^{18}$ De hecho, ya en 1905 Emile Laurent declaraba que todos los seres humanos somos más o menos fetichistas. ${ }^{19}$

En los relatos de Osoro, aunque algunos personajes femeninos son fetichistas, predominan las manifestaciones del fetichismo heterosexual masculino, el cual siempre se centra en torno a la mujer, tanto en representaciones inanimadas de su cuerpo como en partes específicas o prendas del mismo. En este caso, como ya revelara Laura Mulvey en relación al cine, es a través de la mirada masculina como se produce la objetificación o cosificación de la mujer, con la consiguiente anulación de su individualidad y de su propia capacidad de respuesta sexual. ${ }^{20}$ Parece evidente que la idea de que en nuestra sociedad la feminidad resulta difícilmente separable de una sexualización fetichista es algo sobre lo que Jasone Osoro ha reflexionado bastante, y de hecho, abiertamente proclama que en la cultura actual la mujer es un maniquí, y que eso motiva que ella sea feminista. ${ }^{21}$

En la obra de Osoro la sexualidad nunca se muestra desvinculada de las relaciones de poder, un poder que se inserta en unos marcos sociales muy específicos. Así, la sexualidad se presenta como una extensión de unas relaciones humanas que se articulan como campo de batalla, donde uno/a lucha por dominar al otro y donde ya están establecidas unas desigualdades determinadas que influyen de manera decisiva en las posibilidades de la re-

16 Sigmund Freud, 'Fetishism', en The Norton Anthology of Theory and Criticism, ed. Vincent B. Leitch (New York: Norton \& Company, 2001), $952-56$ (p. 953).

17 Louise J. Kaplan llega a indicar que parte de la misoginia que Freud muestra en su ensayo 'Fetishism' se debe a que cuando lo escribió había sufrido una serie de operaciones quirúrgicas en la boca que habrían estimulado su inconsciente identificación con lo femenino, una especie de castración contra la que reacciona infravalorando el cuerpo de la mujer (Cultures of Fetishism [New York: Palgrave Macmillan, 2006], 18).

18 Gamman y Makinen, Female Fetishism, 117.

19 Cit. Valerie Steele, Fetish: Fashion, Sex and Power (New York: Oxford U. P., 1996), 11.

20 Laura Mulvey, 'Visual Pleasure and Narrative Cinema', en The Norton Anthology of Theory and Criticism, ed. Leitch, 2181-92 (p. 2186).

21 Jasone Osoro, 'Feminista naiz', pár. 1. Esta idea la desarrolla más Osoro en su última novela, Greta, en la que la protagonista femenina, Ana, se lamenta de los modelos de belleza a los que se encuentra sometida la mujer: 'Soy una mujer. Una más entre las miles que hay en la calle. No me parezco en nada a esas otras mujeres que salen en las portadas de las revistas. [...] [Ellas] Buscan la perfección, parecerse a las modelos que se ven en los escaparates. Maniquíes de carne y hueso, más hueso que carne, claro. [...] ellos desean a las modelos' (Greta [Barcelona: Seix Barral, 2007], 157). 
alización personal de los individuos. En todos los relatos de Desnudos, las elecciones y el comportamiento de las protagonistas están profundamente ligados no sólo a sus circunstancias psicológicas - el abandono, el temor al rechazo, la depresión -, sino a su localización social en los estratos medios y bajos de una sociedad consumista. Así, en 'Plancha', la mujer que se dedica a coleccionar lencería lo hace sólo después de terminar sus tareas domésticas y, en particular, de planchar la ropa de toda su familia. La protagonista de 'Sombra tornasolada' es, además de ama de casa, costurera, y la de 'Huele a lejía', una ex-prostituta que se dedica a limpiar casas. Finalmente, la 'Rabia' de la protagonista del relato del mismo título se debe no sólo a la infidelidad de su marido, sino a un entorno laboral que le desagrada pero se siente incapaz de cambiar.

Uno de los ejemplos más representativos de la conexión entre sexo y poder y de la reificación de la mujer se encuentra en el cuento significativamente titulado 'La novia de Frankenstein', donde el protagonista, Manu, decide canalizar la obsesión por su vecina de enfrente a través de una muñeca hinchable. ${ }^{22}$ Manu va dotando de accesorios a la muñeca para hacerla parecer a la vecina, ya que sabe que en la vida real jamás podrá poseerla. Este moderno Frankenstein se nos muestra como un ser inseguro, solitario y misántropo, caractervsticas que explicarían su amalgatofilia o fetichismo por las muñecas. Especialmente siente temor por las mujeres, trauma que la autora hace derivar de la experiencia de tener una madre posesiva: 'Se sentía como castrado ante la mayoría de las amas de casa. Manu estaba convencido de que era herencia de su madre. Una madre absorbente, manipuladora, posesiva, celosa y absolutamente carente de glamour. [...] Vivió esposado por el dominio de su madre hasta cumplir los dieciocho'.$^{23}$ En este comentario, desde la perspectiva del personaje masculino se refuerza la visión patriarcal de la mujer dominante como castradora y del hombre como su víctima inocente. Así, el hombre sustituye a la mujer real por una muñeca porque a esta última no la considera amenazante y no corre el peligro de no ser capaz de complacerla. Semejante opinión expresan Lucía Etxebarria y Sonia Núñez-Puente en su ensayo En brazos de la mujer fetiche: 'la

22 Además de fetichismo por la muñeca hinchable, al espiar a su vecina, Manu es un ejemplo típico de voyeur. El voyeurismo o escopofilia consiste en el deseo de mirar escenas sexualmente estimulantes como sustitutas de la actividad sexual real (David W. Allen, The Fear of Looking or Scopophilic-Exhibitionistic Conflicts [Charlottesville: Univ. Press of Virginia, 1974], 1). Como en el caso del fetichismo, se suele relacionar con experiencias de la infancia (ibid., 29). El voyeur generalmente mira lo que sucede dentro de las casas, ya que como explica Dorothy Kalins, la casa es el espacio más íntimo de la ciudad y el tener acceso a ella a través de la mirada supone ser testigo de la privacidad máxima de una persona ('Voyeurism in New York', en The New Eroticism: Theories, Vogues and Canons, ed. Philip Nobile [New York: Random, 1970], 64-76 [p. 67]).

23 Jasone Osoro Igartua, Desnudos (Barcelona: Seix-Barral, 2002), 53. El resto de las citas de esta obra remiten a esta edición. 
muñeca occidental no intenta conectar con la mujer real [...] sino que, por el contrario, supone la huida de ella' ${ }^{24}$

La mujer muerta realiza un papel similar al de la muñeca en las fantasías sexuales masculinas. Como escribe Francisco Umbral, 'la caprichosidad sexual del hombre aspira a la mujer absolutamente dócil [...], y la más dócil es la muñeca o la muerta'. ${ }^{25}$ En la historia principal que enmarca el libro de Osoro, Fermín mata a Rebeca porque así ésta se convierte en la muñeca que no se opondrá a sus deseos. Una vez muerta es cuando Fermín experimenta que ella le pertenece: 'Sintió como nunca que ella era de él. Ahora Rebeca era de cera, pálida, muda, ciega. Rebeca está hecha de jirones de plastilina, trenzada de nácar, hechizada por la hermosura que sólo maquilla la muerte' (10). En esta cita, a través de los adjetivos 'muda' y 'ciega' se expresa el deseo del hombre de poseer una mujer pasiva, que no hable para protestar o pedir ni recrimine con su mirada. Por otro lado, el uso de los sintagmas 'de cera' y 'de plastilina' muestran la clara conexión entre la mujer muerta y la muñeca. La muerta constituye, de hecho, una muñeca en grado máximo. Así, tras matar a Rebeca, Fermín 'juega' con ella: la abraza, le frota con una esponja, le calza unos zapatos de aguja y también la besa. En definitiva, se transforma en su dócil, sumiso y silencioso instrumento de placer. No hay que olvidar, sin embargo, que esta perspectiva de los personajes masculinos se ve contrastada con la de las propias mujeres protagonistas de otros cuentos, que se presentan como luchadoras, sufridas, trabajadoras y a las que los hombres son incapaces de comprender y satisfacer.

La paidofilia o atracción hacia las niñas en el relato 'La bufanda roja' tiene en común con la amalgatofilia y la necrofilia el hecho de que de nuevo es el hombre el que se siente en control en las relaciones sexuales. Estos tres tipos de 'perversiones' le sirven al hombre inseguro para superar las dudas que sufre respecto a su masculinidad. Osoro desarrolla el fetichismo por las niñas a través de la historia de María, una gitana que tiene cuatro años cuando Álex la recoge de la calle y que se convierte en el entretenimiento preferido del joven: 'María era como una muñequita para Álex. Una polichinela de feria. Él era como un padre para la niña' (89). La niña representa, por tanto, a una muñeca andante y el hombre se siente poderoso porque se cree dueño de ella: 'Álex era feliz porque sabía que María era suya, y que nada ni nadie la arrebataría de su lado. Nunca jamás' (89). Sin embargo, a diferencia de la muñeca y de la mujer muerta, la niña posee una voluntad propia, y esto le sirve a la autora para crear un personaje que se venga de la sociedad patriarcal que silencia y muñequiza a las mujeres. De esta manera, Osoro transforma a María en una niña perversa al estilo del personaje de Vladimir Nabokov: 'abandonó su timidez y su silueta de Campanilla se tornó una fugaz Lolita’ (92). Al final,

24 Lucía Etxebarria y Sonia Núñez Puente, En brazos de la mujer fetiche (Barcelona: Destino, 2002), 318.

25 Francisco Umbral, El fetichismo (Madrid: El Observatorio, 1986), 113. 
tras suministrale un somnífero a Álex, María baila para él y le clava unas agujas de coser en el corazón. Por lo tanto, en el cuento la niña angelical objeto de las fantasías masculinas se transforma en una niña capaz de vencer al hombre y de triunfar sobre su dominación. Ahora bien, esta victoria se da dentro de un marco que no cuestiona, sino, antes bien, reproduce, la relación dominador-dominado, así como el imaginario patriarcal. En efecto, la figura de la femme fatale, la mujer perversa que devora al hombre, o de la niña que ya en su infancia posee el instinto destructor contra el varón es un estereotipo de larga tradición cultural y literaria. ${ }^{26}$ Más aún, el hecho de que la niña sea de raza gitana provoca que a la otredad genérica y sexual se una la racial. En el poema que antecede al relato, 'Flamenco', se halla la misma estereotipación de la raza gitana con ciertas resonancias lorquianas: 'La muerte era una gitana / cardando penachos con peinetas de plata' (87).

Otros relatos de Osoro se ocupan de la dimensión fetichista del hombre por ciertas partes del cuerpo femenino o determinados elementos de la feminidad normativa. Se trata de la fragmentación o desmembración del cuerpo femenino, qu e de nuevo se relaciona con la objetificación y anulación de la individualidad de la mujer. Un ejemplo de ello es el fetichismo por el cabello largo que aparece en el libro de Osoro. En opinión del psicoanalista Charles Berg, el poder fetichista del cabello se debe a que el subconsciente realiza un desplazamiento del pelo púbico al pelo de la cabeza. ${ }^{27}$ La connotación sexual del cabello se aprecia ya en las expresiones con que la narradora describe el pelo de Rebeca: 'rabo de plumas', 'cálido como el primer beso' y 'carbón espumoso' (11). ${ }^{28}$ La veneración que Fermín siente por el pelo de Rebeca ilustra este fetichismo, y por este motivo, aunque lo intenta, no puede raparle la cabeza.

26 En opinión de Elizabeth K. Menon, la característica principal de la mujer fatal es la de provocar la destrucción inconscientemente o buscar la venganza conscientemente (Evil by Design: The Creation and Marketing of the Femme Fatale [Urbana: Univ. of Illinois Press, 2006], 4). Este modelo de mujer se desarrolló especialmente en el siglo XIX, sobre todo a través de Salomé, pintada por Gustave Moreau en 1876. Patrick Bade considera que la proliferación de la mujer fatal en el arte y la literatura decimonónicas se debió a la ansiedad masculina ante los avances de la mujer nueva en el espacio público (Femme Fatale: Images of Evil and Fascinating Women [New York: Mayflower, 1979], 23). Sin embargo, las encarnaciones femeninas de la maldad monstruosa están presentes en toda la historia occidental. Así, se encuentran mujeres fatales en la Biblia, como Eva, Judith o Jezabel; en el imaginario mitológico, como Helena, Fedra o Medea; o en la literatura, como Carmen, Lulú o Lolita (Enrique Gil Calvo, Máscaras masculinas: héroes, patriarcas y monstruos [Barcelona: Anagrama, 2006], 81).

27 Cit. Etxebarria y Núñez-Puente, En brazos de la mujer fetiche, 282.

28 A la propia Osoro se la podría considerar fetichista del cabello, ya que reconoce que siempre lo ha tenido largo, y que como Sansón, si se lo cortara, sentiría que perdería la fuerza ('Ilea mostuz gero, indarra galduko nuke'; http://www.matraka.info/elkar. php?zenbakia=7943 pár. 2). Así, el pelo parece actuar como un arma de poder para la mujer, al igual que los zapatos de tacón, como se comentará más adelante. 
Otro de los fetiches que se halla en el libro es el de los labios pintados de carmín rojo. En el relato 'Motus moti', a Óscar le atraen las mujeres con los labios pintados y por eso le regala a Julia una barra de carmín distinta cada día que salen juntos. Como en el caso del cabello femenino, la explicación de este fetiche parece residir en la transposición que realiza el hombre entre los labios y el órgano sexual femenino. Por otro lado, los labios pintados de rojo, debido a la asociación entre este color y la sangre, resultan sexualmente estimulantes para el hombre porque connotan lascivia y son un símbolo de la tentación femenina. ${ }^{29}$ De hecho, Osoro relaciona los labios rojos con la mujer sexualmente activa, incluso dominadora. Así, al usar carmín rojo, Julia se metamorfosea en una mantis religiosa: 'Julia agarró la cara del muchacho, lo acercó y le comió la boca. Era como si, de repente, la delicada muchacha estuviera poseída por el alma de aquel insecto' (106). Pero es en el último cuento del libro donde más claramente aparece la capacidad letal de los labios femeninos. Rebeca es consciente de que va a morir en manos de Fermín, por lo que decide pintar óleo teñido en veneno debajo del carmín púrpura de sus labios para que Fermín muera en cuanto los bese. Aquí la mujer otra vez consigue vencer al hombre y vengarse de la fuerza bruta ejercida sobre ella sirviéndose de los mismos mecanismos que generan su opresión. En este sentido, Osoro construye unos personajes femeninos poderosos, pero que no pueden dejar de funcionar dentro de un marco de relaciones en el que el único medio del que disponen para triunfar es su sexualidad y su capacidad de seducción. ${ }^{30}$

A pesar de que tradicionalmente se ha prestado mayor atención a las tendencias fetichistas masculinas, críticos como Naomi Schor, Emily Apter, David Kunzle, Lorraine Gamman y Merja Makinen han demostrado que las mujeres también pueden tener una fascinación obsesiva con componente sexual. Sin embargo, en los relatos de Osoro las mujeres suelen centrar el fetichismo en objetos suyos que les ayudan a transformarse en algo que desean ser, o que les ofrecen una imagen más positiva de ellas mismas. En este sentido, los cuentos parecen confirmar la opinión de Freud de que todas las mujeres son fetichistas de la ropa. ${ }^{31} \mathrm{El}$ ejemplo más representativo al respecto es la narración titulada 'Plancha', en la que la protagonista siente obsesión por su lencería:

29 Aparte de los labios y la sangre, el color rojo es recurrente a lo largo de toda la obra en elementos como las cerezas y la bufanda de María.

30 En la narrativa erótica femenina española, no es extraño que la mujer se vengue del hombre. Algunos ejemplos son los cuentos significativamente titulados 'La castigadora', 'La vengadora' y 'La presa', incluidos en Alevosías, de Ana Rossetti; o el cuento 'En los parques, al anochecer', de Marina Mayoral, donde una maestra de escuela viaja por el extranjero $y$, tras ser violada, busca encuentros sexuales furtivos con hombres para después matarlos.

31 Cit. Lorraine Gamman, 'Self-Fashioning, Gender Display, and Sexy Girl Shoes: What's at Stake-Female Fetishism or Narcissism?', en Footnotes: On Shoes, ed. Shari Benstock y Suzanne Ferriss (New Brunswick: Rutgers U. P., 2001), 93-115 (p. 100). 
[...] todos los meses compro al menos un conjunto de braga y sujetador. Me muero por los colores, por las flores, los encajes. Me pirran los tangas, las ligas, los bodys y las combinaciones transparentes. Eso sí, yo sólo me pongo los sencillos, los blancos y los negros. El resto ... El resto son para mí como tener una colección de arte. (24)

La explicación que la propia protagonista ofrece sobre su adicción a comprar y coleccionar ropa interior resulta reveladora: 'Mi psicoanalista dice que la indiferencia de mi marido ha originado mi obsesión por la lencería. îYo qué sé! Me da igual. Las manos y las caricias de mi marido hace tiempo que no me excitan. Pero me apasiona lavar a mano mi pequeño tesoro' (25). Por lo tanto, el fetichismo de la protagonista surge como respuesta a la vida sexual insatisfactoria de su matrimonio, lo que coincide con la noción de 'homeovestismo' que desarrolla Louise Kaplan. La mujer homeovestida es aquella que se viste con ropa claramente femenina, que se 'enmascara' de feminidad porque se siente insegura y que fetichiza su propio cuerpo debido a la ansiedad sexual. ${ }^{32}$ En el relato de Osoro, la satisfacción que el personaje experimenta al manipular su lencería no es exclusivamente de tipo sexual, sino que más bien se debe al deseo de huir de su rutina doméstica - sin dejarla totalmente de lado, ya que al fin y al cabo su escape viene a través del planchado de ropa-. La ropa interior ofrece a esta mujer, ama de casa y con una vida aburrida, la posibilidad de sentirse atractiva y convertirse en una figura icónica, en un objeto sexual:

Y cuando [la plancha] aún estaba caliente, con el cálido aire entre sus hilos, sentía un inmenso placer probándome todos y cada uno de los conjuntos. Me ponía delante del espejo e imaginaba que era ... que era ... que era un maniquí. Que vivía en un lujoso escaparate, rodeada de libidinosas miradas, hechizadas miradas que deseaban vestir y tocar mi ropa interior. Soñaba que era bailarina de strip-tease, una diana perfecta para viciosos sedientos de placer. (25)

En este fragmento, el disfrute de la mujer de su propio cuerpo en frente del espejo encierra un componente claramente narcisista. Asimismo, la posición de la protagonista es la de asumir su condición de fetiche, de mercancía. Como indica John Berger, las mujeres fetichizan su ropa y se objetifican a sí mismas como consecuencia de haber internalizado la mirada masculina. En su opinión, mientras que los hombres miran a las mujeres, éstas se miran a sí mismas: 'A woman must continually watch herself; she is almost continually accompanied by her own image of herself'. ${ }^{33}$ De hecho, la diferencia en la forma en que los dos sexos experimentan la sexualidad se muestra claramente al final de este relato, cuando la protagonista se encuentra planchando su ropa interior medio desnuda y el cobrador del gas la intenta violar.

32 Louise J. Kaplan, Female Perversions: The Temptations of Emma Bovary (London: Pandora, 1991), 262.

33 John Berger, Ways of Seeing (Harmondsworth: Penguin, 1972), 46. 
La fantasía de ser admirada en la distancia en la que la propia mujer ejerce el control queda transgredida por la violencia masculina, que interpreta esa fantasía personal como una incitación a la violencia. Es interesante resaltar que esta misma historia que aquí se narra desde el punto de vista de la mujer se relata desde el punto de vista masculino heteronormativo en otro de los cuentos, 'La novia de Frankenstein', en el que Manu presencia el suceso desde el piso de enfrente:

Y vio que el chaval revisaba el gas mientras ella seguía planchando, cantando, bailando. Enseñando entre vuelta y vuelta su atrevida lencería. Provocando la inocente mirada del revisor, incitándolo al pecado. Manu no se extrañó cuando el chico se abalanzó sobre la vecina. (55-56)

A través de esta doble perspectiva, Osoro refleja la distinta mentalidad que tienen el hombre y la mujer respecto al sexo y al fetichismo. Para cierto tipo de hombre heterosexual, una mujer ligera de ropa está buscando tener relaciones sexuales, mientras que para una mujer, el estar en ropa interior puede significar simplemente un momento de dedicación a sí misma y a la contemplación de su cuerpo. Además, obviamente existe una diferencia entre querer ser deseada (en abstracto), como sucede en este caso, y querer tener relaciones sexuales con el primer hombre que aparezca. Al final, la chica deja inconsciente al revisor con un golpe de plancha, llama a la policía y sigue planchando y bailando mientras tararea la emblemática canción 'I will survive', de Gloria Gaynor. ${ }^{34}$

Para interpretar adecuadamente cuál de las dos perspectivas de esta historia defiende la autora, hay que acudir al poema que precede a 'Plancha', 'Temblores'. En él, a través de una pesadilla del yo poético, Osoro desarrolla en detalle el sentimiento de repugnancia que padece la mujer ante una relación sexual no deseada: 'Estabas encima de mí, / follándome. / Tu obeso jadeo. / Tu voz hecha nudos. / Tus dedos de lija. / Tu barriga de oliva. / Tus labios de caracol. / Tus ojos desorbitados, / sobreexcitados. / Tus muslos de piedra. / [...] Tu pene alienígena' (21). En estos versos, con el uso de los paralelismos sintácticos, Osoro fragmenta y deconstruye el cuerpo del hombre. Además, crea una imagen monstruosa de él por medio de adjetivos y de sintagmas que connotan pesadez y reproducen la aversión de la mujer. La expre-

34 En la versión original en euskera, Osoro no incluye la referencia a la canción de Gaynor, lo que indica que posteriormente pensó que 'Sobreviviré' resultaba un lema adecuado para la mujer que se encuentra bajo el dominio del hombre. En general, en la traducción al español, Osoro apenas modifica los cuentos. Lo único que se aprecia es una tendencia a eliminar explicaciones accesorias. Por ejemplo, en 'La novia de Frankenstein', en la versión en euskera se dice que el protagonista vio la película Frankenstein y pensó que se parecía al monstruo, comentario que después se elimina en la traducción para que sea el lector el que a partir del título del relato realice esta conexión (Korapiloak [Donostia: Elkar, 2001], 51). 
sión 'tu pene alienígena' resulta especialmente significativa porque hace referencia al falo como un instrumento ajeno y opresor para la mujer. ${ }^{35}$

Además de la ropa interior femenina, en Desnudos los zapatos de tacón también se erigen en objetos de idolatría. De hecho, según Valerie Steele, los zapatos de tacón se han convertido en el fetiche más normalizado en la cultura contemporánea, ya que forman parte de un tipo de feminidad normativa, de seducción, aunque también representan una cultura física y alegóricamente opresiva para la mujer. ${ }^{36}$ Generalmente, el tacón se ha considerado un símbolo fálico, un sustituto del pene, pero como indica Lorraine Gamman, también es posible interpretarlo como una vagina simbólica que acoge al pie. ${ }^{37}$ La explicacióón de Freud a la podolatría masculina residía en el hecho de que el niño mira los genitales de la madre desde abajo y los asocia con los zapatos. ${ }^{38}$ Por otro lado, el hombre también puede sentirse atraído por los zapatos de tacón porque cuando la mujer los calza, se acentúan numerosas características que se suelen conectar con el atractivo sexual femenino, como el movimiento de las caderas, la prominencia de las nalgas y la curvatura de la espalda. ${ }^{39}$ A algunas mujeres, la altura y la estilización proporcionadas por los zapatos de tacón les hace sentirse poderosas y atractivas. Por este motivo, es común encontrar a mujeres que reconocen coleccionar zapatos y que no se avergúenzan de ello y, de hecho, la cultura de masas tiende a fomentar este tipo de fetichismo - recuérdense las numerosas conversaciones sobre zapatos en la serie televisiva Sex and the City -. Asimismo, la obsesión por los zapatos podría calificarse como un tipo de fetichismo que ya se ha normalizado a través de la influencia de la moda y la comercialización a gran escala. Lo mismo podría decirse de la manera en que ciertas prendas y materialeslos corsés, el cuero, las cadenas - inicialmente asociados con una sexualidad masoquista o 'perversa' han pasado a formar parte de los circuitos comerciales más accesibles y a ser requeridos por un público de clase media.

En el relato 'Nudos', Osoro presenta la relación entre las mujeres y los zapatos a través de la opinión de la dueña de una zapatería, cuyo nombre, 'Divina', resulta de por sí revelador:

[Las mujeres] se 'visten' con tacones. Los tacones les permiten marcar el paso en lugar de seguirlo, una mujer normal y corriente se transforma en una vampiresa capaz de conseguir que los hombres

35 Osoro se muestra especialmente concienciada por los casos de violencia doméstica: 'Eta azken datu beldurgarri bat. Martxoaren 8an gaude eta dagoeneko 14 emakume hil dira estatu espainiarrean beren bikotekideek erailda. Arrazoi gehiago behar al dira feminista izateko?' ('Feminista naiz', pár. 1) ('Y un último dato escalofriante. Estamos a ocho de marzo y ya han muerto catorce mujeres en el estado español asesinadas por sus parejas. ¿Se necesitan más razones para ser feminista?').

36 Steele, Fetish: Fashion, Sex and Power, 109.

37 Gamman, 'Self-Fashioning, Gender Display, and Sexy Girl Shoes', 101.

38 Freud, 'Fetishism', 954.

39 Steele, Fetish: Fashion, Sex and Power, 111. 
caigan rendidos a sus pies. [...] Una mujer que lleva tacones nunca es débil. Al contrario, es mucho más fuerte que cualquiera $\mathrm{y}$, sobre todo, muchísimo más poderosa. (126-27)

De nuevo tenemos que considerar la perspectiva del hablante: Divina es una artista jubilada que ve el mundo en términos dramáticos, como una representación. Desde su particular punto de vista los zapatos son, como en los cuentos de hadas, el medio para escapar de la rutina (127), así como un arma de seducción a través de la cual la mujer es capaz de dominar al hombre. ${ }^{40}$ El otro lado de ese argumento es que un calzado que impide caminar normalmente y que deforma los pies no puede considerarse, en última instancia, un instrumento de liberación: al contrario, podría decirse que es un objeto que perpetúa la fantasía sexual masculina. En este sentido, se puede aplicar a la obra de Osoro una de las principales objeciones que Barbara Morris y Lou Charnon-Deutsch realizan de Las edades de Lulú (1989), de Almudena Grandes: que tras lo que se presenta como agencia sexual de la mujer se esconde una visión patriarcal de la sexualidad femenina. ${ }^{41}$ En cualquier caso, la mayor ironía de este cuento es que todo el proceso de aprender a andar con tacones y aceptar el sufrimiento que el estar 'divina' implica lo lleva a cabo no una mujer, sino un hombre, Sergio, quien finalmente acaba trabajando de pescadero porque la zapatería cierra por la apertura de un centro comercial.

En general, en el libro de Osoro los personajes femeninos buscan liberarse de las ataduras patriarcales y experimentan la búsqueda del placer fuera de las convenciones sociales. Como indica Janet Pérez, el análisis del cuento femenino erótico demuestra que el estereotipo de que la mujer es incapaz de separar el amor del sexo resulta erróneo. ${ }^{42}$ A diferencia de otras narradoras contemporáneas, las protagonistas de la escritora vasca no necesitan ser

$40 \mathrm{Al}$ igual que la protagonista de este relato, ya desde la década de los ochenta, algunas feministas han defendido la utilización de los zapatos de tacón y del maquillaje alegando que hacen sentir bien a la mujer (Gamman, 'Self-Fashioning, Gender Display, and Sexy Girl Shoes', 96). Ésta es la posición que defiende Lucía Etxebarria, para quien se puede ser feminista y vestirse de manera femenina: 'El sentirse feminista no significa que una no pueda pintarse los labios o ponerse tacones o falda el día que quiera vestirse para seducir. [...] La cuestión radica en la palabra elección, pues existe una diferencia entre perder peso y maquillarse porque una desea conscientemente seducir y llamar la atención o hacerlo porque si no se va a considerar alienada, una paria sin derecho a gratificación sexual o a un puesto en el mercado laboral' (En brazos de la mujer fetiche, 411).

41 Barbara Morris y Lou Charnon-Deutsch, 'Regarding the Pornographic Subject in Las edades de Lulu', Letras Peninsulares, 6:2-3 (1993-94), 301-19 (pp. 312-13).

42 Janet Pérez, 'Characteristics of Erotic Brief Fiction by Women in Spain', Monographic Review/Revista Monográfica, 7 (1991), 173-95 (p. 192). Otras características que Janet Pérez señala para los relatos femeninos eróticos son la preocupación por la elaboración artística de la prosa, la descripción física breve, la sátira o el humor y la variedad temática, incluyendo aspectos como la soledad existencial (ibid., 191-93). Todos estos rasgos son aplicables a los cuentos de Jasone Osoro. 
jóvenes ni hermosas para buscar o encontrar la satisfacción sexual. Por ejemplo, en 'Carpe diem', una mujer de más de sesenta y cinco años descubre su instinto sexual y comienza a trabajar para una línea erótica; mientras que en 'El amor es un puzzle', la protagonista determina casarse con un motero mucho más joven que ella. Por otro lado, otros personajes femeninos deciden poner fin a relaciones sentimentales que no funcionan y sólo continúan por la rutina. En este sentido, Osoro presenta una visión desencantada del matrimonio. La mayoría de las protagonistas de Desnudos rondan la mediana edad, y las que están casadas o descubren el adulterio del marido, o terminan aburridas de su vida conyugal no satisfactoria porque el hombre no es capaz de entenderlas ni de darles placer. En el poema 'Fuego', Osoro reitera esta idea al referirse a dos amantes: 'Casados, / desenamorados' (57). Similar hastío se halla en la descripción que de su matrimonio realiza Esther, la protagonista de 'Sombra tornasolada':

Todas las noches eran iguales, un besito de buenas noches pellizcado al aire y hasta mañana. Bueno, siempre menos cuando le entraba el calentón, porque era peor todavía. Se ponía encima de mí, me penetraba y vaciaba su gancho ante mi fría mirada de cristal, mis fingidos gemidos y mis movimientos de funambulista sin red. A esto se limitaba mi vida de casada. (29-30)

Ante la cotidianeidad y la falta de felicidad de su vida matrimonial, a Esther se le presenta la oportunidad de acostarse con un joven actor, que aparentemente representa lo opuesto a su rutina matrimonial. Sin embargo, al poco de quedarse dormidos, la protagonista despierta por unos ronquidos iguales a los de su marido, ante lo cual determina que es mejor estar sola que mal acompañada: 'Decidí que no quería compartir mi cama con nadie. Ni con un marido, ni con un amante. A partir de los cincuenta, una valora dormir bien, a pierna suelta. En todo caso, un buen polvo y listo' (38). En este sentido, Osoro se diferencia de otras autoras contemporáneas como Rosa Montero o Laura Freixas, que también han tratado el tedio y el aburrimiento de la pareja en sus relatos, pero desde una óptica mucho más optimista, ya que terminan transmitiendo la idea de que las parejas que apenas se hablan en realidad se quieren, o que es mejor un matrimonio aburrido que la soledad. ${ }^{43} \mathrm{Ja}$ sone Osoro resulta más radical que estas escritoras, seguramente porque es más joven que ellas. Sus personajes femeninos prefieren estar solas antes que continuar en una relación que es una farsa. De hecho, su opinión personal así lo atestigua: 'Niretzat importantea da ez egotea norbaitekin ohitura edo

43 En Amantes y enemigos, Rosa Montero escribe que 'el amor es una mentira, pero funciona' (Amantes y enemigos: Cuentos de parejas [Madrid: Alfaguara, 1998], 276). Semejante a ella resulta Laura Freixas, en cuyo relato 'La noche', de Cuentos a los cuarenta, la protagonista piensa que es mejor un matrimonio aburrido que la soledad: 'Pero ahora tengo cuarenta y sé que o eso o ¿qué? ... ¿Usted cree que es preferible la soledad? Yo creo que no' (Cuentos a los cuarenta [Barcelona: Destino, 2001], 79). 
inertzia hutsez. Harreman bat lagatzea hastea baino askoz zailagoa da beti, baina tristea da bakarrik ez gelditzeagatik, beldurragatik, jarraitzea' ('Para mí es importante no estar con alguien por costumbre o por pura inercia. Romper una relación es siempre mucho más difícil que empezarla, pero es triste continuar por no quedarse sola o por miedo').${ }^{44}$ Además de cuestionar la vida matrimonial, Osoro también deconstruye la creencia de que existe el 'hombre ideal' o el 'príncipe azul'. Desde su punto de vista, en la realidad el amor no coincide con la imagen de felicidad suprema de los cuentos infantiles, los cuales sólo sirven para crear falsas ilusiones a muchas niñas y mujeres. Así lo expresa en el poema 'La boda': 'Besé a la rana. / Pero la rana croó' (27). ${ }^{45}$

En cierto modo, se puede decir que en Desnudos Osoro realiza un alegato feminista para que las mujeres encuentren, tanto en lo sexual como en lo personal, el tipo de vida que realmente desean. Según el libro, para ello la mujer tiene casi siempre que enfrentarse al dominio del hombre. En una entrevista Osoro ha comentado que, en su opinión, las mujeres están en desventaja en la sociedad respecto a los hombres y que todavía no existe igualdad entre los dos sexos: 'Boterea gizonezkoen esku dago. Pixkanaka ari gara urratsak ematen, baina oraindik berdintasunetik urruti gaude. [...] Eta, gainera, etxeko esparrua oraindik gure denez, ez da horren erraza lanarekin bateratzea' ('El poder está en manos de los hombres. Poco a poco estamos dando pasos, pero todavía estamos lejos de la igualdad. [...] Y, encima, como el ámbito de la casa todavía es nuestro, no es tan fácil igualarse en el trabajo'). ${ }^{46}$ Seguramente para compensar esta situación, Osoro crea unas protagonistas fuertes que cada vez que pelean contra el hombre en última instancia triunfan. Lo que resulta problemático es que a la mujer casi siempre se la representa de manera victimista, algo que, en su análisis de la narrativa de Etxebarria, Akiko Tsuchiya considera que entra en contradicción con la transgresión de los tabúes sexuales. ${ }^{47} \mathrm{Al}$ construir personajes femeninos que constantemente

44 Unanue, 'Jasone Osoro', pár. 13.

45 En su primer libro de relatos, Tentazioak ('Tentaciones'), Osoro ya desmitificaba algunos cuentos infantiles. En 'Txanogorritxuren inozentzia' ('La inocencia de Caperucita Roja'), el Lobo deja de ser feroz y agresivo para convertirse en un voyeur; en 'Fantasia sexualak' ('Fantasías sexuales'), Blancanieves resulta ser sexualmente activa; mientras que en 'Ménage átrois', el Príncipe tiene relaciones sexuales con las hermanastras de la Cenicienta (Tentazioak [Donostia: Elkarlanean, 1998], 53-57, 99-101, 125-28). En su última novela, Greta, Osoro también deconstruye el cuento de la Cenicienta al hacer que se rompa el tacón del zapato de cristal que la protagonista se prueba con su traje de novia, y que ésta se diga a sí misma: 'Ya no creo en príncipes azules' (153). Osoro no es la única escritora contemporánea del estado español que subvierte los cuentos infantiles tradicionales. Espido Freire, Mercedes Abad y Rosa Montero, entre otras, también revisan y modifican las clásicas historias de príncipes y princesas.

46 Unanue, 'Jasone Osoro', pár. 6.

47 Akiko Tsuchiya, 'Gender, Sexuality, and the Literary Market in Spain at the End of the Millennium', en Women's Narrative and Film in Twentieth-Century Spain, ed. Ferrán y Glenn, 238-55 (p. 249). 
se encuentran dominados física y emocionalmente por el hombre, Osoro nos muestra que las mujeres también pueden ser victimarias en la sociedad y oprimir a otras mujeres o a los hombres. Por otro lado, su visión pesimista de las relaciones entre hombres y mujeres a veces resulta desalentadora. El hombre se representa como el enemigo de la mujer, lo que provoca que no parezca factible la construcción de una sociedad en la que convivan en armonía todos sus miembros.

Como se ha visto, Jasone Osoro se sirve del fetichismo para explorar la feminidad y la situación de la mujer en una sociedad occidental urbana, capitalista y comercializada. En los relatos en los que los personajes masculinos centran el fetichismo en versiones inanimadas de la mujer o en partes del cuerpo femenino, se aprecia el temor del hombre a la mujer real o una incapacidad para comprenderla. La mujer muerta, la muñeca o la niña le sirven al hombre para canalizar sus temores a la castración y asegurar su masculinidad ejerciendo el control. A través de la reificación, el fetichista no corre el peligro de que la mujer de carne y hueso le recrimine que no es capaz de satisfacerla. Por su parte, el fetichismo de los personajes femeninos por su ropa interior o los zapatos de tacón se explica también como una solución a sus inseguridades. La mujer se siente narcisísticamente bella, plena de confianza y poderosa cuando viste prendas que enaltecen su feminidad y su atractivo físico.

El análisis de los fetichismos de estos relatos manifiesta las tensas relaciones de poder existentes entre los hombres y las mujeres. El sexo se convierte en un instrumento de dominio: mientras que el hombre fetichista cosifica a la mujer, anulando su subjetividad, la mujer fetichista, como respuesta, se reifica a sí misma para contrarrestar el dominio físico del hombre. Así, diversos personajes femeninos como Rebeca y la niña gitana consiguen triunfar sobre la violencia masculina utilizando sus armas de seducción. Otro ejemplo se encuentra en el relato 'Rabia', en el que la protagonista se venga del adulterio de su marido interrumpiendo la felación que le está realizando. Aunque en todos estos casos la mujer se está defendiendo del abuso del hombre, al final se transmite el mensaje de que el único medio del que dispone la mujer para vencer al hombre es el sexo. De esta manera, la mujer se representa como seductora y devoradora del hombre, lo que refuerza la imagen patriarcal de la femme fatale.

En los relatos de Osoro, no sólo hay desencuentros entre los hombres y las mujeres en el plano sexual, sino también en las relaciones de pareja. La autora vasca desidealiza el matrimonio al crear unos personajes femeninos que descubren el adulterio de sus maridos o que sufren de falta de cariño. En definitiva, el hombre no es capaz de satisfacer ni sexual ni emocionalmente a la mujer, por lo que ésta ve la soledad como una solución placentera y enriquecedora. El problema de esta perspectiva es que se simplifican las relaciones sentimentales, ya que en la realidad la mujer puede ser tan culpable como 
el hombre de que su matrimonio no funcione. En general, en la obra domina el individualismo, entendiendo éste como la necesidad de que cada persona encuentre su propio yo. Ésta es una de las originalidades de Desnudos, obra que resulta también innovadora en cuanto al estilo, con la alternancia entre poema y relato, y la reaparición de personajes de un cuento en otro.

La dueña de la tienda de zapatos le revela a su aprendiz una de las ideas principales que se obtienen de la lectura del libro: 'La vida está hecha de pesados nudos que tenemos que ir soltando hasta quedarnos desnudos' (131-32). Jasone Osoro plantea en su obra la liberación de los nudos-como el título original en euskera indica-que impiden el desarrollo personal y constriñen la libertad. Los prejuicios sociales y sexuales, la violencia de género, los matrimonios dominados por el hastío, la propia internalización de las normas que nos oprimen son algunas de las ataduras que lastran a los personajes de esta obra. En un mundo mercantilizado, jerárquico y automatizado, la posibilidad de metamorfosis del individuo, aunque sea temporal, se ofrece como un refugio necesario contra la rutina, el vacío y la identidad fija que la sociedad nos asigna. 